\title{
Challenges and Policy Suggestions on the Development of Hydrogen Economy in China
}

\author{
Wei Shan ${ }^{1,2}$, Fang-Fang Wang ${ }^{3,}$ \\ ${ }^{1}$ School of Economics, Sichuan University, China \\ ${ }^{2}$ School of Economics and Management, Wenzhou University Oujiang College, China \\ ${ }^{3}$ School of Business, Wenzhou University, China
}

\begin{abstract}
In recent years, with the intensification of environmental damage, mankind is at a crossroads towards the next energy revolution. Hydrogen energy, because of its pollution-free nature, has become the focus of technological research and development in many countries, and the economic pattern around it is taking shape China's investment in the field of new energy has been increasing in recent years, and the prospect of hydrogen economy has prompted China to continuously increase the development of hydrogen energy. However, it faces many obstacles, both technical and social. The Chinese government is now using financial subsidies to help hydrogen companies incubate. However, with the development of the industry, China is currently facing great obstacles in large-scale commercial application, intellectual property protection and innovation, standardization construction and social confidence. This paper believes that policy measures such as selective commercial distribution, innovation system building, industry standardization construction and social education can be adopted to help solve these challenges
\end{abstract}

\section{Introduction}

Hydrogen energy, as a secondary energy, can be produced from a variety of primary energy, such as coal, oil, natural gas, solar energy, wind energy, hydropower, tidal energy, geothermal energy, nuclear fuel, etc. can be directly or indirectly produced hydrogen energy and then converted into electricity. Not so with secondary sources such as petrol and diesel, which are produced almost entirely on fossil fuels. With the increasing consumption of fossil fuels and the dwindling reserves of these resources, there is an urgent need to find a new and abundant energy source that does not depend on fossil fuels. Hydrogen energy is a kind of new secondary energy which is expected to solve the conventional energy crisis.

China currently has the world's largest hydrogen production capacity. China produced 16 million tons of hydrogen in 2012, rising to 20 to 22 million tons in 2018. Therefore, China has a good production base to meet the potential demand of the future hydrogen economy, known in China as the "hydrogen energy industry." According to the 2016 blue book on "Infrastructure Development of Hydrogen Industry in China", which compiled by

Corresponding author: wff2005@126.com 
China Institute of Standardization and Institute of Technology, by 2020, 72 billion cubic meters of hydrogen will be used for energy, and the industry's total industrial output will reach 300 billion yuan ( $\$ 44.4$ billion). This will increase further to 1 trillion yuan $(\$ 148$ billion) by 2030 and 4 trillion yuan ( $\$ 59.2$ billion) by 2050 .

Recently, the China Hydrogen Energy Alliance released its first white paper on hydrogen and fuel cell industry in China. The alliance founded in February 2018, and is led by China Energy Investment Corporation, and its members come from a number of universities and other well-known companies such as Linde, Air Products, Air Liquide. According to the document, the value of the hydrogen industry will reach rmb1tn $(\$ 148 \mathrm{bn})$ between 2020 and 2025, with 50,000 fuel-cell vehicles in service and 200 refuelling stations. From 2026 to 2035, the industry's industrial output will jump to rmb5tn ( $\$ 740 \mathrm{bn})$ and $15 \mathrm{~m}$ fuel-cell vehicles will be equipped with up to 1,500 refuelling stations. By 2050 , hydrogen will account for 10 per cent of China's energy system, total demand will reach $60 \mathrm{~m}$ tonnes and annual economic output will exceed rmb10tn $(\$ 1.48 \mathrm{tn})$, the report added.

Despite the development of hydrogen economy is prosperous, the challenges are also evident. Based on the findings of Gong (2018) and the recently released statistical survey data, this paper makes a detailed analysis of the three challenges facing the development of hydrogen economy: (1) commercial scale application; (3) intellectual property protection and innovation; (4) safety standards and social confidence.

\section{Challenges for Hydrogen Industry}

\subsection{Large-scale commercial application}

At present, the large-scale commercial application of hydrogen energy still faces many challenges. In terms of hydrogen production, most of the existing hydrogen production technologies rely on primary energy sources such as coal and natural gas, and the economic and environmental problems are still prominent. Although the Hydrogen production and power generation system with zero net $\mathrm{CO} 2$ emission based on coal and supercritical water gasification proposed by Guo and Jin [1] effectively reduces carbon emissions, it is still considered to be pollution-prone to some extent [2]. The use of nuclear energy and biomass gasification to produce hydrogen is not yet mature, and the use of renewable energy such as solar energy or wind energy has low efficiency and high comprehensive cost [3-4].

In terms of hydrogen storage, although pressurized compression hydrogen storage technology, liquefied hydrogen storage technology, metal hydride hydrogen storage technology and organic compound hydrogen storage technology have all made great progress, the balance between hydrogen storage density, hydrogen storage safety and hydrogen storage cost has not been resolved, and there is still a certain gap from large-scale commercial application [5]. From the perspective of hydrogen use, the insufficient scale of hydrogen fuel cell vehicles leads to the high construction cost of hydrogen filling stations and difficulty in large-scale laying. In turn, the insufficient number of hydrogen filling stations makes it difficult for users to choose hydrogen fuel cell vehicles [6]. In general, it is difficult to combine the convenience and cost control of hydrogen industry.

\subsection{Intellectual property protection and innovation}

Developing hydrogen technology and infrastructure requires substantial investment, particularly in intellectual property, which can be an advantage for countries with strong innovation cultures and research capabilities. The trend is likely to shift countries' strategic focus from simply chasing energy supplies to strengthening infrastructure capacity and 
management system efficiency at the same time. As a result, in a world where renewable energy is the main source of energy, investment and technology have increasingly become sources of cooperation or nodes of geopolitical competition.

In the longer term, tensions over technology transfer between developing and developed countries have increased. Spending on renewable energy research among countries is a mix of geopolitical considerations as well as economic or environmental ones. Trade barriers disputes over photovoltaic cooperation between China and the EU or trade wars between China and the us are based on competition over intellectual property rights in energy technology are existing cases. In the future, countries will increasingly compete for renewable energy infrastructure. Asia has considerable renewable energy and accounts for a large share of the development of renewable energy. Whoever can seize the opportunity of renewable energy infrastructure in Asia will greatly enhance its geopolitical influence.

From the perspective of global hydrogen patent layout, a large number of core patents are in the hands of large enterprises in the United States, Japan and other countries, while China has not yet become the leading technology source of international hydrogen development. Most of the foreign patent applicants are multinational enterprises with strong strength, which have absolute leading technology advantages and capital advantages in the industry, while most of the domestic patent applicants are universities and scientific research institutes, which have weak applied technology basic research ability and low product transformation rate. In addition, foreign multinational enterprises, led by Toyota and Honda, have a strong awareness of patent protection and a clear strategic intention of international patent layout, and have applied for a considerable number of PCT patents in many countries. In contrast, Chinese research and development institutions lack awareness of patent protection and apply for fewer patents abroad, which is not conducive to future market competition and expansion.

\subsection{Safety standards and social confidence}

At present, the global academia and industry have reached a consensus that as long as the development of the hydrogen industry in accordance with the standards, the degree of safety can be guaranteed. According to incomplete statistics, taking water and hydrogen energy as an example, its security application as a new energy has been very mature. Compared with gasoline and diesel, hydrogen-water fuel has low calorific value, high flash point, not easy to ignite, high explosion limit, far less harmful than gasoline and diesel, high boiling point, high latent heat of vaporization, low volatilization, and lower on-site concentration than gasoline and diesel. Therefore, some scholars believe that filling stations with hydrogen fuel is safe, and vehicles can also ensure safety in driving. However, according to data from 100 consumers in Jiangsu province, the willingness to buy hydrogen cars in the near term is clearly low. The skeptical crowd, however, expressed widespread concerns about safety and a low level of trust in Chinese-made hydrogen products. But this concern is not groundless, at present China hydrogen safety technology investment is not much. It can be mainly reflected in the lack of high pressure hydrogen cycle fast charging and discharging fatigue test equipment, the lack of high sensitivity hydrogen leakage detection system and other key detection equipment, at the same time, more serious is the hydrogen safety detection research ability temporarily unable to meet the needs of hydrogen energy development. In addition to the shortcomings of the above standardization construction, this paper also believes that there are still large misunderstandings in the society's cognition of hydrogen energy. Alanne [7] once conducted a questionnaire survey on 93 Finnish students majoring in energy engineering to understand the cognition and cognition of hydrogen technology of college students. The results showed that the questionnaire before and after the homework improved students' knowledge and cognition 
of hydrogen technology. The biggest changes occurred in their knowledge of hydrogen safety and their willingness to acquire a home hydrogen system. However, the current Chinese society's coverage of various technologies is still not objective and enough. For example, after an explosion in Zhangjiakou in late 2018 that killed 23 people, media once linked the explosion to the hydrogen industry. Although later proved to be a rumor, but also caused public concern about the safety of hydrogen energy. Although China still needs to work hard on the establishment of hydrogen energy standardization, there are more than 21 hydrogen energy standards for the existing infrastructure in China, which are considered mature for the management of existing safety issues. So, how to build up society's confidence in hydrogen energy is still an urgent problem to be solved..

\section{Policy suggestions}

\subsection{Selective Commercial distribution}

The utilization of hydrogen energy still faces many obstacles, and too much political will and financial support will be detrimental to the development of hydrogen energy industry before major technological breakthroughs and significant cost reductions are achieved. The social and economic development status of our country cannot bear the huge cost of the hydrogen energy economy transformation which has not a clear prospect for a period of time. In view of the current situation in China, this study believes that the location conditions should be taken into consideration in the layout of hydrogen energy industry, and the development ideas and positioning should be clarified. Priority should be given to the development of hydrogen energy industry in such aspects as military use, space development, energy supply in remote areas, combination with renewable energy and small-scale commercial co-generation of heat and power.

Hydrogen can come from a wide range of sources, including hydrogen production from fossil fuels, hydrogen production from hydrogen-containing materials, hydrogen recovery from chemical byproducts, and hydrogen production from solar and wind energy. Hydrogen production from fossil fuels includes coal gasification to produce hydrogen, natural gas reforming to produce hydrogen and methanol cracking to produce hydrogen; Hydrogen production from hydrogen-containing substances includes hydroelectrolysis to produce hydrogen, ammonia decomposition to produce hydrogen and sodium borohydride hydrolysis to produce hydrogen; hydrogen recovery from chemical byproducts includes caustic soda, coke and light oil cracking.

Tian [8] believes that there are various production modes of hydrogen, and the economics of technology routes need to be analyzed according to regional resource endowment. Hydroelectrolysis is the process of injecting purified water into an electrolyzer with direct current. The water molecules undergo electrochemical reaction on the electrode and decompose into hydrogen and oxygen. Most of the cost of hydroelectrolytic hydrogen production is in electric energy. If there is cheaper off-peak electricity, the cost of hydrogen production will be greatly reduced. At present, Zhangjiakou, Hebei and other places have built a million kilowatt wind power demonstration base, due to wind abandon and power limit pressure, in Guyuan county, China's first comprehensive utilization of wind power hydrogen demonstration project. But for regions such as Datong in Shanxi Province, where coal reserves are abundant and coal chemicals are developed, hydrogen can be produced at a lower cost by gasification. In the long run, of course, technology should still be used to reduce the potential pollution from coal to hydrogen.

Adaptive Subsidy 
At present, the hydrogen industry in China is very hot, but most regions lack the fuel cell vehicle industry, and there is also a lack of understanding of fuel cell vehicles. A considerable number of regions have introduced hydrogen industry support policies, but few have introduced specific policies for fuel cell vehicles, indicating that there is still a considerable distance from the industrialization of fuel cell. Of the eight regions that have introduced local subsidy policies, four have received land subsidy at a 1:1 ratio with the state subsidy, while only one region has received land subsidy at a ratio of less than 1:0.5. It is far higher than in 2018, all regions have attached great importance to fuel cell vehicles. This partly reflects the state's high subsidies for hydrogen, which have led to a rush of capital and a scramble to develop the industry in places that do not have the natural endowments of the "hydrogen economy". In this regard, this study encourages the development of market-oriented hydrogen energy industry, reasonably formulate subsidy policies, actively cultivate the market base, and promote the efficient development of hydrogen production, hydrogen storage and hydrogen use.

The localization rate of China's hydrogen energy industry chain is very fast. However, the primary problem of hydrogen energy industry is the cost, which needs to be reduced by mass quantification as soon as possible. However, the Ministry of Finance and other four departments jointly issued the notice on 'Further improving the financial subsidy policy for the promotion and application of new energy vehicles'. The transition period is from March 26, 2019, to June 25, 2019, according to the notice. After the end of the transition period, purchase subsidies for new energy vehicles (except buses and fuel cell vehicles) will no longer be provided, and the purchase subsidies will be concentrated on supporting the construction of weak links in infrastructure such as charging (hydrogenation) and supporting operation services. Long-term implementation of subsidy policy, so that some enterprises suffer from policy dependence, it is difficult for them to deal with global market competition. The latest subsidies remove some support for hydrogen development, and provides a strong signal for the future of hydrogen industry. The hydrogen industry urgently needs to provide more information to strengthen the subsidy determination of policy makers, at the same time, policy makers need to weigh the pros and cons and strengthen the strategic determination of subsidies. This paper suggests that, in the development of the hydrogen, the cancellation of the subsidy in a certain extent can stimulate the potential of the market. However, in the case that hydrogen energy is still in the preliminary stage, subsidies for hydrogen energy are more necessary to formulate different subsidy measures according to different products and enterprise sizes, and the current subsidy policies should not ignore these heterogeneities.

\subsection{Innovation system building}

The national development and reform commission and national energy bureau released the revolutionary energy technology innovation action plan (2016-2030). It "explicitly mentioned, by 2030 , to build sound energy technology innovation system that compatible with national conditions. The improvement of our capacity for independent energy innovation, and make energy technology reached the international advanced level, will help coordinate sustainable development of energy industry in China, and let China enter the world's energy technology powerhouse. The action plan pointed out that although China's energy science and technology level has made great progress and significantly improved, but compared with the world's power in energy science and technology and leading the energy revolution requirements, there is still a big gap.

In order to cope with the competition of intellectual property in the current international market, this paper argues that the government should play its guiding role. First, it is necessary to strengthen enterprises' awareness of efficient patent protection, 
enhance the intensity of participating in the international market competition, do a good job in international patent application and distribution, and actively seize the commanding heights of scientific and technological innovation. The second is to encourage and strengthen the cooperation between universities and enterprises with traditional technology advantages, combine the advantages of all parties, promote the research, development and application of core technologies, and maximize the market value of technological innovation achievements through patent licensing, patent transfer and other forms. The practical measures of realizing these two points should be to give play to the promotion role of government mechanism, regard technological innovation as the foundation of national progress, establish a complete reward mechanism for researchers who make major breakthroughs in core technology, and establish certification mechanism for relevant enterprises. In addition, at the level of national investment in scientific research, overseas talents should be introduced, and scientific research institutions in regions with superior hydrogen energy endowment should be cultivated.

\subsection{Industry standardization construction and social education}

The safety of hydrogen energy is the focus of the society. The international and domestic application practice has proved that the safety of hydrogen energy can be guaranteed as long as hydrogen energy is produced, stored and used in accordance with standards and regulations. In terms of the hydrogen and fuel cell standard system construction, the hydrogen standardization technical committee (SAC/TC 309) and the national fuel cells and fluid flow battery standardization technical committee (SAC/TC 342) so far, a total of 26 hydrogen related national standards, fuel cell related national standards, 41, Chinese hydrogen energy and fuel cells preliminarily established national standard system framework. It is undeniable that in the process of promoting the hydrogen energy industry, relevant standards in the field of hydrogen energy in China still need to be further improved, and there are still some uncoordinated and unmatched problems. The degree of integration with international standards also needs to be improved. Therefore, it is necessary to further strengthen the standardization work to support the development of hydrogen energy industry and give full play to the supporting and leading role of the standard to the industrial development. We suggest that the state increase investment in hydrogen energy safety, promote hydrogen energy safety based on the study of the causes, mechanisms and consequences of hydrogen accidents, as well as the methods of accident prediction, early warning and control, and formulate reasonable safety technical specifications and standards. Based on the concept of intrinsic safety, equipment/facilities should be designed to establish a sound quantitative assessment system for hydrogen energy utilization risk, prevent and reduce hydrogen energy safety accidents, and promote the healthy and safe development of hydrogen energy industry.

In addition, the public's acceptance of hydrogen energy needs more scientific popularization and education, in which the efforts of the government and scientific research institutions are needed. Although current concerns about safety are normal, there is a need to prevent social panic and opposition. Let the public more fully understand the characteristics of hydrogen energy, production and use of the correct way to avoid possible safety problems. Just as coal and natural gas were just beginning to become common, governments should play an important role as educators. In addition, as the Alanne [7] study argues, system-level approaches should be integrated into hydrogen education, not just the teaching of chemical reactions or hydrogen technology. Both radical and traditional problem sets are needed to cultivate students' creative thinking and keep realistic. 


\section{References}

1. Guo, L., \& Jin, H. Boiling coal in water: hydrogen production and power generation system with zero net co2 emission based on coal and supercritical water gasification. International Journal of Hydrogen Energy, 38(29), 12953-12967, (2013)

2. Chen, J., Fan, Y., Zhao, X., Jiaqiang, E., Xu, W., Zhang, F., ... \& Liu, S. Experimental investigation on gasification characteristic of food waste using supercritical water for combustible gas production: Exploring the way to complete gasification. Fuel, 263, 116735, (2020)

3. Yan, X. L., \& Hino, R. Nuclear hydrogen production handbook (CRC press, 2016).

4. Eriksson, E. L. V., \& Gray, E. M. Optimization and integration of hybrid renewable energy hydrogen fuel cell energy systems-A critical review. Applied energy, 202, 348-364, (2017)

5. Klumpp, F. Comparison of pumped hydro, hydrogen storage and compressed air energy storage for integrating high shares of renewable energies-potential, costcomparison and ranking. Journal of Energy storage, 8, 119-128, (2016)

6. Gis, W., \& Schaap, G. Hydrogenation of road transport on the example of Sweden and Poland. IOP Conference Series: Materials Science and Engineering, 421(4), 042024, (2018)

7. Alanne, K. A survey of finnish energy engineering students' knowledge and perception of hydrogen technology, International Journal of Hydrogen Energy, 43(22), 10205-10214, (2018)

8. Tian, M., Yuen, H. C., Yan, S. R., \& Huang, W. L. The multiple selections of fostering applications of hydrogen energy by integrating economic and industrial evaluation of different regions. International Journal of Hydrogen, 44(56), 2939029398, (2019) 